Caries Res. 1978;12(Suppl. 1):I-III

\title{
Contents, Vol. 12, Supplement 1, 1978
}

\section{Preface 1}

Bibby, B. G.: Dental Caries 3

Backer Dirks, O.; Künzel, W., and Carlos, J. P.:

Caries-Preventive Water Fluoridation 7

Marthaler, T. M.; Mejía, R.; Tóth, K., and Vines, J. J.: Caries-Preventive Salt Fluoridation ... 15

Binder, K.; Driscoll, W. S., and Schützmannsky,

G.: Caries-Preventive Fluoride Tablet Pro

grams 22

Fehr, F. R. von der and Møller, I. J.: Caries-

Preventive Fluoride Dentifrices

Birkeland, J. M. and Torell, P.: Caries-Preven

tive Fluoride Mouthrinses 38

Brudevold, F. and Naujoks, R.: Caries-Preventive Fluoride Treatment of the Individual ... 52

Newbrun, E. and Frostell, G.: Sugar Restriction

and Substitution for Caries Prevention 65

Frostell, G. and Ericsson, Y.: Anti-Plaque Thera

peutics in Caries Prevention 74

Heløe, L. A. and König, K. G.: Oral Hygiene and Educational Programs for Caries Prevention . 83

Ericsson, Y. and Hardwick, L.: Individual Dia

gnosis, Prognosis and Counselling for Caries

Prevention 94

Silverstone, L. M.: Operative Measures for Caries

Prevention 103 